\title{
Demonstration of a socially transmitted flavor aversion in rats? Kuan and Colwill (1997) revisited
}

\author{
BENNETT G. GALEF, JR., and ELAINE E. WHISKIN \\ McMaster University, Hamilton, Ontario, Canada
}

\begin{abstract}
In each of three experiments that differed only in procedural detail, observer rats interacted with pairs of conspecific demonstrators, one fed a cocoa-flavored diet (Diet Coc) and the other a cinnamonflavored diet (Diet Cin). Immediately after both members of a pair of demonstrators had been fed, and 5 min before they interacted with an observer or observers, one of the demonstrators was made ill by intraperitoneal injection with lithium chloride. After interacting with a pair of demonstrators for $15 \mathrm{~min}$, each observer was allowed to choose between Diet Cin and Diet Coc for $22 \mathrm{~h}$. In all three experiments, observer rats consumed as much Diet Cin after interacting simultaneously with both an ill demonstrator that had eaten Diet Cin and a healthy demonstrator that had eaten Diet Coc as after interacting simultaneously with both a healthy demonstrator that had eaten Diet Cin and an ill demonstrator that had eaten Diet Coc. These results raise questions about the generality of Kuan and Colwill's (1997) demonstration of socially transmitted flavor aversions in Norway rats.
\end{abstract}

A number of laboratories have found that after a naive "observer" rat (Rattus norvegicus) interacts with a recently fed conspecific "demonstrator," the observer exhibits an enhanced preference for whatever food its demonstrator ate (e.g., Galef, Whiskin, \& Bielavska, 1997; Galef \& Wigmore, 1983; Heyes \& Durlach, 1990; PosadasAndrews \& Roper, 1983; Strupp \& Levitsky, 1984). Evidence of comparable social transmission of food aversions has proven considerably more difficult to provide; in many circumstances, observer rats exposed to recently fed sick or unconscious demonstrators do not avoid the foods their respective demonstrators ate. To the contrary, when observer rats are presented with a choice between the diet eaten by an ill demonstrator and an unfamiliar equipalatable diet, the observers show an enhanced preference for, not an aversion to, the food their ill demonstrator ate (Galef, McQuoid, \& Whiskin, 1990; Galef \& Stein, 1985; Galef, Wigmore, \& Kennett, 1983; Grover et al., 1988).

Failure to find evidence of social transmission of a taste aversion from ill demonstrator rats to their conspecific observers is surprising for several reasons. First, on functional or evolutionary grounds, observer rats should surely not learn socially to eat foods that may well have caused illness in an unwell demonstrator. Second, in other species,

This research was supported by Natural Sciences and Engineering Research Council of Canada Grant 0GP0000307 to B.G.G. The authors thank Lynne Honey, David White, and Mertice Clark for critiques of earlier drafts of the manuscript. Correspondence should be addressed to B. G. Galef, Jr., Department of Psychology, McMaster University, Hamilton ON, L8S 4K1 Canada (e-mail: galef@mcmaster.ca). social transmission of learned aversions is easy to demonstrate (Mason, Arzt, \& Reidinger, 1984). Last, previous research has shown both that diet-identifying cues emitted by demonstrator rats are effective conditioned stimuli (Galef et al., 1983) and that rats made ill by injection with lithium chloride $(\mathrm{LiCl})$ are effective unconditioned stimuli in standard taste-aversion learning studies (e.g., Bond, 1982; Coombes, Revusky, \& Lett, 1980).

It was, therefore, a welcome development when Kuan and Colwill (1997) published results of a carefully designed experiment in which observer rats showed less enhancement of their preference for a distinctively flavored food after interacting with an ill demonstrator that had eaten that food than after interacting with a healthy demonstrator that had eaten it.

The procedures used by Kuan and Colwill (1997) in demonstrating social learning of a flavor aversion differed in numerous ways from the methods used in experiments that failed to produce the effect. In discussion of their successful demonstration of social transmission of a learned aversion, Kuan and Colwill focused on two facets of their experimental design that they felt were crucial to their success. First, in Kuan and Colwill's procedure, but not in procedures failing to demonstrate social learning of flavor aversions, observer rats were equally familiar with the two diets that they were offered in the choice test that followed interaction with demonstrators. Second, the relatively brief (15-min) period of interaction between demonstrator and observer used by Kuan and Colwill (but not the $30-\mathrm{min}$ or 2 -h periods of interaction used in experiments failing to provide evidence of social transmission of flavor aversions) made it 
unlikely that demonstrators would begin to recover from toxicosis while they were still interacting with their observers. Consequently, the opportunity for extinction of socially learned aversions may have been present in unsuccessful procedures, but not in Kuan and Colwill's successful one.

There were, of course, numerous other differences between Kuan and Colwill's (1997) procedures and those used in experiments that failed to find social learning of flavor aversions. For example, in the Kuan and Colwill experiment, (1) the concentration of the $\mathrm{LiCl}$ solution used to induce toxicosis was greater than that used in other studies, (2) observers interacted simultaneously rather than sequentially with demonstrators, (3) demonstrators and observers interacted in an unfamiliar environment, whereas in other studies demonstrators and observers often interacted in observers' home cages, (4) observers interacted with the same demonstrators on two successive days, whereas in other experiments, each observer interacted only once with each demonstrator, and (5) adult male rats served as demonstrators and observers, whereas in other experiments, young female rats served in these roles.

We anticipated that, by systematically comparing the food choices of observers exposed to procedures that incorporated various aspects of Kuan and Colwill's (1997) successful methods of demonstrating social learning of food aversions into our own unsuccessful methods (Galef et al., 1990; Galef et al., 1983), we would be able to identify features critical for success. Describing boundary conditions on transmission of learned aversions would be useful in two ways. First, it would indicate limits on the circumstances under which such social learning would be expected to occur in free-living Norway rats. Second, it might provide useful clues as to the adaptive function of socially learned aversions in natural circumstances (Galef \& Whiskin, 1994).

\section{EXPERIMENT 1}

In Experiment 1, we incorporated into our basic methods (Galef et al., 1983) those two features of the Kuan and Colwill (1997) procedure that Kuan and Colwill felt were most important in allowing social learning of flavor aversions to occur. First, like Kuan and Colwill, before we offered each observer rat a choice between cinnamonand cocoa-flavored diets for $22 \mathrm{~h}$, we allowed each observer to interact simultaneously with two demonstrator rats: one that had eaten cinnamon-flavored diet and one that had eaten cocoa-flavored diet. Second, $5 \mathrm{~min}$ before we placed a pair of demonstrators with an observer, we injected one demonstrator with the same dose of $\mathrm{LiCl}$ as had Kuan and Colwill, and we then left observers to interact with their respective demonstrators for only $15 \mathrm{~min}$. Also, like Kuan and Colwill, we paired demonstrators with their respective observers on 2 successive days, in case successful demonstration of social learning of fla- vor aversions depended on repeated exposures of observers to demonstrators.

\section{Method}

Subjects. Eighteen 56-day-old, experimentally naive, female Long-Evans rats obtained from Charles River Canada (St. Constant, Quebec) served as observers. An additional thirty-six 70-day-old rats that had served as observers in other studies of social transmission of food preferences served as demonstrators in the present experiment. It may be relevant to note that the subjects, both in this experiment and in Experiments $2 \mathrm{~A}$ and 2B, were of different strain (Long-Evans vs. Sprague-Dawley), sex (female vs. male), age (juvenile vs. adult), and history of laboratory experience than were subjects in Kuan and Colwill's (1997) study.

Apparatus. Throughout the experiment, we housed all subjects individually in stainless steel hanging cages measuring $35.6 \times 20.3$ $\times 20.3 \mathrm{~cm}$. Semicircular, stainless steel cups, $10 \mathrm{~cm}$ in diameter and $5 \mathrm{~cm}$ deep, held food presented to the subjects. By filling each cup with food to a depth of less than $2 \mathrm{~cm}$, we prevented spillage.

Diets. We prepared two diets by mixing either $20.0 \mathrm{~g}$ of Hershey's Pure Cocoa (Diet Coc) or $10.0 \mathrm{~g}$ of McCormick's Fancy Ground Cinnamon (Diet Cin) with 1,000 g of powdered Purina Rodent Laboratory Chow 5001 (Ralston Purina, Woodstock, Ontario).

Procedure. To begin the experiment, we placed all 36 demonstrator rats on a 23-h/day food-deprivation schedule, and, for 2 successive days, we fed them powdered Purina Rodent Laboratory Chow 5001 for $1 \mathrm{~h} /$ day. For $1 \mathrm{~h}$ following a third 23-h period of food deprivation, we fed 18 of the demonstrators Diet Cin and the remaining 18 demonstrators Diet Coc. We then injected 9 of the 18 demonstrators fed each diet intraperitoneally with a $5-\mathrm{ml} / \mathrm{kg} 0.6-\mathrm{M}$ $\mathrm{LiCl}$ solution, the same dose Kuan and Colwill (1997) used to induce toxicosis in their subjects.

Approximately $5 \mathrm{~min}$ after injection, we placed 1 demonstrator that had just eaten Diet Cin and 1 demonstrator that had just eaten Diet Coc in the home cage of each observer. A demonstrator that we poisoned with $\mathrm{LiCl}$ immediately after it ate Diet $\mathrm{Cin}$ is designated a Cin-P demonstrator, and a demonstrator that was not injected with $\mathrm{LiCl}$ after it ate Diet Coc is designated a Coc-NP demonstrator. Each observer interacted simultaneously either with both $1 \mathrm{Cin}-\mathrm{P}$ demonstrator and 1 Coc-NP demonstrator or with both 1 Coc-P demonstrator and 1 Cin-NP demonstrator.

After $15 \mathrm{~min}$, we removed both demonstrators from each observer's home cage, returned the demonstrators to their respective home cages (where no food was available), and placed two weighed food cups (one containing Diet Cin and the other containing Diet $\mathrm{Coc}$ ) in each observer's cage. Twenty-two hours later, we removed the food cups, weighed them, and determined the amount of each diet eaten by each observer.

During the last hour that the observers were offered a choice of Diets Cin and Coc, we fed each demonstrator the diet other than that which it had eaten the preceding day, then injected those demonstrators that had not been injected the preceding day with $\mathrm{LiCl}$ solution. We then waited approximately $5 \mathrm{~min}$, placed the same pair of demonstrators into each observer's home cage that we had placed there the preceding day, and again let the observer and the demonstrators interact for $15 \mathrm{~min}$. Following the 15 -min period of interaction, we removed demonstrators from the experiment and again gave the observers a choice, for $22 \mathrm{~h}$, between weighed samples of Diets Cin and Coc.

\section{Results and Discussion}

The main results of Experiment 1 are presented in Figure 1A, which shows, separately for each of the two 22-h periods of observer testing, the mean amount of Diet Cin 


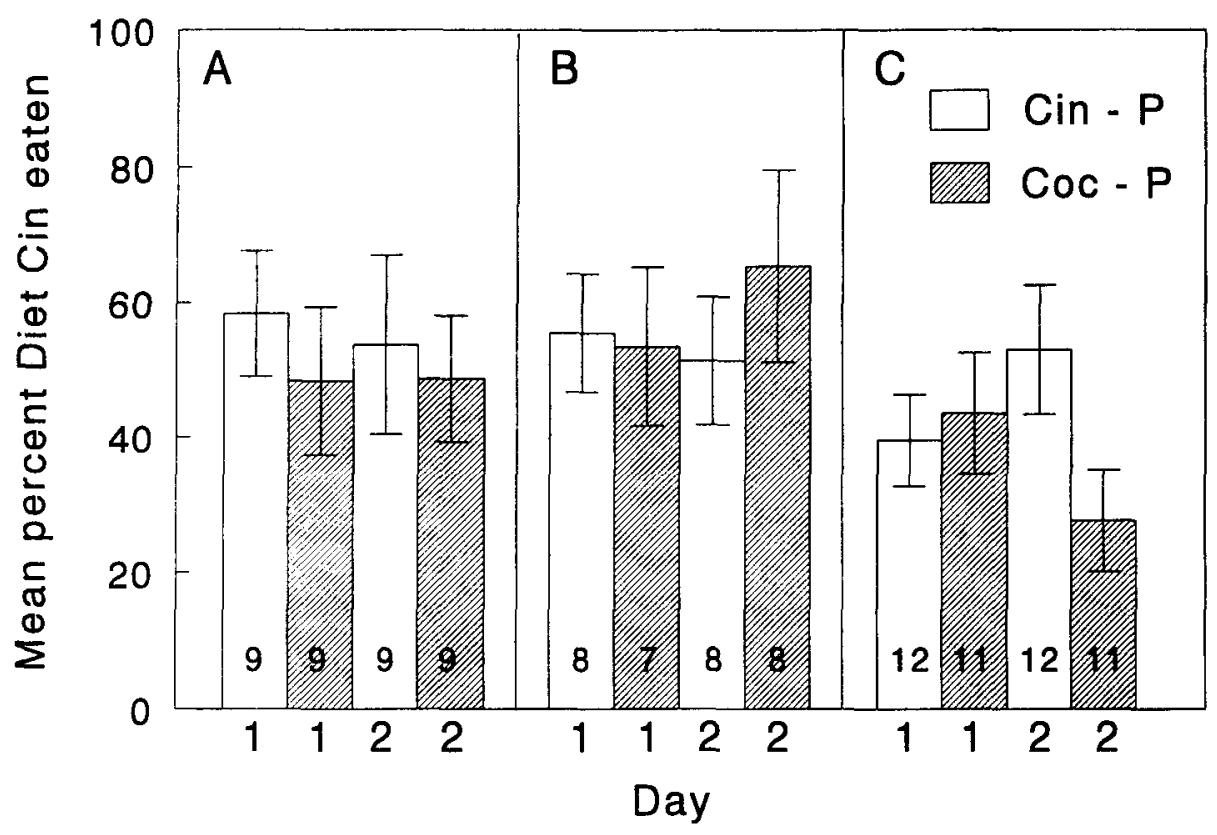

Figure 1. Mean amount of cinnamon-flavored diet (Diet Cin) as a percentage of total amount consumed during 22-h choice tests by the observer rats that were subjects in (A) Experiment 1, (B) Experiment 2A, and $(C)$ Experiment 2B. Members of Cin-P groups interacted with a demonstrator that ate Diet Cin and was poisoned and a demonstrator that ate Diet $\mathrm{Coc}$ and was not poisoned. Members of Coc-P groups interacted with a demonstrator that ate Diet Coc and was poisoned and a demonstrator that ate Diet $C i n$ and was not poisoned. Error bars $= \pm 1 S E M$. Numbers inside histograms $=N /$ group.

(as a percentage of total amount consumed during $22 \mathrm{~h}$ ) eaten by the observer rats that interacted with either both a Cin-P and a Coc-NP demonstrator or both a Coc-P and a Cin-NP demonstrator. As can be seen in Figure 1, during both 22-h test periods, the observers ate as much Diet Cin after interacting with both a Cin-P and a Coc-NP demonstrator as after interacting with both a Cin-NP and a Coc-P demonstrator.

The results of Experiment 1 offer no support for the hypothesis that relatively brief periods of interaction between demonstrator and observer and equal prior exposure of observers to the two diets offered to them during testing permit social transmission of a learned flavor aversion.

\section{EXPERIMENT 2}

Given the failure in Experiment 1 to find social learning of a flavor aversion using procedures that Kuan and Colwill (1997) suggested might be sufficient to produce that result, we decided to replicate as closely as possible all aspects of the procedure used by Kuan and Colwill. We conducted two versions of Experiment 2: the first (Experiment 2A) was carried out exactly as described in Kuan and Colwill; the second (Experiment 2B) was conducted with a single modification of Kuan and Colwill's procedures. In Experiment 2B, instead of allowing each pair of demonstrators to interact with a pair of observers during the 15-min period of interaction between demonstrators and observers, we allowed each pair of demonstrators to interact with a single observer. We hoped that allowing demonstrators to interact with only 1 observer at a time might increase the amount of exposure of each observer to its demonstrators and thus increase the probability of detecting social learning of flavor aversions.

\section{Method}

Subjects. In Experiment 2A, 16 experimentally naive, 56-dayold, female, Long-Evans rats served as observers. An additional sixteen 63- to 70-day-old female rats that had served as observers in other studies served as demonstrators in Experiment $2 \mathrm{~A}$. It should be noted that our subjects differed in strain, sex, and age from Kuan and Colwill's (1997) subjects.

In Experiment 2B, 24 experimentally naive, 56-day-old, female, Long-Evans rats served as observers. An additional forty-eight 63 to 70 -day-old female rats that had served as observers in other studies served as demonstrators in Experiment 2B.

Apparatus. The apparatus was identical to that used in Experiment 1 except that we used standard $35.6 \times 27.9 \times 16.5 \mathrm{~cm}$, shoebox rat cages as venues for interaction between the demonstrator rats and their observers.

Procedure. The procedure of Experiment $2 \mathrm{~A}$ was that described in detail in Kuan and Colwill (1997). In brief, we first accustomed pairs of demonstrator and observer rats to maintenance at $80 \%$ of 
normal body weight. We then fed one member of each pair of demonstrators Diet Cin and the other Diet Coc for $1 \mathrm{~h}$. We next injected one member of each pair of demonstrators with a $5-\mathrm{ml} / \mathrm{kg} 0.6-\mathrm{M} \mathrm{LiCl} \mathrm{so-}$ lution and, 5 min later, introduced a pair of demonstrators and a pair of observers into a shoe-box cage, where they remained for $15 \mathrm{~min}$.

At the end of the 15-min period of interaction, we returned the observers and the demonstrators to their home cages and offered each observer weighed samples of both Diets Cin and Coc. The next day, we again fed each demonstrator the same diet that it had eaten the preceding day and then injected with the $\mathrm{LiCl}$ solution the pair member that we had not injected with the $\mathrm{LiCl}$ solution the previous day. Again, we (1) waited $5 \mathrm{~min}$, (2) placed each pair of demonstrator rats together with the same pair of observer rats with which the demonstrators had interacted on the preceding day, (3) let demonstrators and observers interact for $15 \mathrm{~min}$, and (4) offered each observer a choice between weighed samples of Diets Cin and Coc for $22 \mathrm{~h}$.

At the end of each 22-h feeding period, we determined how much of each diet each observer had eaten and calculated the percentage of each observer's total intake during the 22 -h period that was Diet Cin.

We also conducted an exact replication of Experiment $2 \mathrm{~A}$ using as subjects another 16 observers and 16 demonstrators.

The procedure of Experiment $2 \mathrm{~B}$ was identical to that of Experiment $2 \mathrm{~A}$ except that, on both days when the demonstrators and the observers interacted, each pair of demonstrators interacted in a shoebox cage with a single observer rather than with a pair of observers.

Data analyses. We used both between-subjects and withinsubjects measures of social transmission of aversion. We made two assumptions. First, we expected that if members of a group of observer rats learned an aversion to either Diet Cin or Diet Coc as a result of interacting, respectively, with $\mathrm{Cin}-\mathrm{P}$ or Coc-P demonstrator rats, then in both Experiment $2 \mathrm{~A}$ and Experiment 2B, on each day of observer testing, the mean percentage of the observers' total intake that was Diet Cin would be less following interaction with Cin $-\mathrm{P}$ and Coc-NP demonstrators than following interaction with Cin-NP and Coc-P demonstrators. Second, we expected that if the observer rats learned an aversion to the diet eaten by the poisoned demonstrators, then the percentage of each observer's total intake that was Diet Cin would be less during the $22 \mathrm{~h}$ after it interacted with Cin-P and Coc-NP demonstrators than during the $22 \mathrm{~h}$ after it interacted with Coc-P and Cin-NP demonstrators.

\section{Results and Discussion}

Data were lost from 1 observer on the first day of testing in Experiment 2A and from 1 observer on each day of testing in Experiment 2B when they failed to eat more than $3 \mathrm{~g}$ of food during the 22-h test period.

Between subjects. The main results of Experiments $2 \mathrm{~A}$ and $2 \mathrm{~B}$ are presented, respectively, in Figures $1 \mathrm{~B}$ and $1 \mathrm{C}$. As can be seen in Figure 1, there was no suggestion that the observers in either Experiment 2A or Experiment 2B ate less Diet Cin after interacting with Cin-P and Coc-NP demonstrators than after interacting with Coc-P and Cin-NP demonstrators. Indeed, on Day 2 of Experiment 2B, the observers exposed to Cin-P and Coc-NP demonstrators ate reliably more (not less) Diet Cin than did the observers exposed to Cin-NP and Coc-P demonstrators [Mann-Whitney $U$ test, $U(12,11)=33, p<.05$ ]. Of course, given the number of paired comparisons that can be made using the data presented in Figure 1 (an analysis of variance would not be appropriate because the subjects were not randomly assigned to groups across experiments), finding a single statistically "significant" comparison was not particularly informative. However, the finding repeated in all three panels of Figure 1 -that the observers did not eat more of the diet eaten by their unpoisoned demonstrators than by their poisoned demonstrators-is highlighted by this unexpected, statistically reliable finding.

The outcome of the replication of Experiment 2A was identical to that reported for Experiment 2A: We found no effect of poisoning demonstrators on the food choices of their observers.

Within subjects. Comparison of the percentage of Diet Cin eaten by individual observers after interacting with Cin-P and Coc-NP and Cin-NP and Coc-P demonstrators led to the same conclusion as did the data presented in Figure 1. In both replications of Experiment 2A, 8 observers ate a greater percentage and 8 observers ate a smaller percentage of Diet Cin after interacting with Cin-P and Coc-NP demonstrators than after interacting with Cin-NP and Coc-P demonstrators. In Experiment 2B, 1 observer ate equal percentages of Diet Cin on the 2 test days, 15 observers ate a greater percentage of Diet Cin after interacting with Cin-P and Coc-NP demonstrators than after interacting with Cin-NP and Coc-P demonstrators, and only 7 observers ate a greater percentage of Diet Cin after interacting with Cin-NP and Coc-P demonstrators than after interacting with Cin-P and Coc-NP demonstrators (sign test, $p=.134$ ).

No data from either Experiment 2A or Experiment 2B offered any support for the hypothesis that Norway rats learned a flavor aversion as the result of interacting with a demonstrator rat that had eaten a diet and was suffering toxicosis.

In conclusion, the results of Experiments 1,2A, and 2B suggest that social learning of a flavor aversion by rats, as reported by Kuan and Colwill (1997), is either a relatively fragile phenomenon or specific to rats of as yet undefined strain, sex, or age. In either case, as Kuan and Colwill suggested in discussion of the results of their experiment, in Norway rats, social learning of flavor aversions is a less generalizable phenomenon than is social learning of flavor preferences.

\section{REFERENCES}

BoND, N. W. (1982). Transferred odor-aversions in adult rats. Behavioral \& Neural Biology, 35, 417-421.

Coombes, S., Revusky, S. H., \& LeTt, B. T. (1980). Long-delay tasteaversion learning in an unpoisoned rat: Exposure to a poisoned rat as the unconditioned stimulus. Learning \& Motivation, 11, 256-266.

GALEF, B. G., JR., MCQuoid, L. M., \& WhisKIN, E. E. (1990). Further evidence that Norway rats do not socially transmit learned aversions to toxic baits. Animal Learning \& Behavior, 18, 199-205.

GALEF, B. G., JR., \& STEIN, M. (1985). Demonstrator influence on observer diet preference: Analyses of critical social interactions and olfactory signals. Animal Learning \& Behavior, 13, 31-38.

Galef, B. G., JR., \& Whiskin, E. E. (1994). Passage of time reduces effects of familiarity on social learning: Functional implications. Animal Behaviour, 48, 1057-1062.

Galef, B. G., JR., Whiskin, E. E., \& Bielavska, E. (1997). Interaction with demonstrator rats changes their observers' affective responses to flavors. Journal of Comparative Psychology, 111, 393-398. 
GaLeF, B. G., JR., \& WIGMORE, S. W. (1983). Transfer of information concerning distant foods: A laboratory investigation of the "informationcentre" hypothesis. Animal Behaviour, 31, 748-758.

Galef, B. G., JR., Wigmore, S. W., \& Kennett, D. J. (1983). A failure to find socially mediated taste aversion learning in Norway rats (R. norvegicus). Journal of Comparative Psychology, 97, 458-463.

Grover, C. A., Kixmiller, J. S., Erickson, C. A., Becker, A. H. Davis, S. F., \& Nallan, G. B. (1988). The social transmission of information concerning aversively conditioned liquids. Psychological Record, 38, 557-566.

Heyes, C. M., \& Durlach, P. J. (1990). "Social blockade" of tasteaversion learning in Norway rats ( $R$. norvegicus): Is it a social phenomenon? Journal of Comparative Psychology, 104, 82-87.

KUAN, L.-A., \& ColwILL, R. M. (1997). Demonstration of a socially transmitted taste aversion in the rat. Psychonomic Bulletin \& Review, 4, 374-377.

Mason, J. R., ARzt, A. H., \& Reidinger, R. F. (1984). Comparative assessment of food preferences and aversions acquired by blackbirds via observational learning. Auk, 101, 796-803.

Posadas-Andrews, A., \& Roper, T. J. (1983). Social transmission of food-preferences in adult rats. Animal Behaviour, 31, 265-271.

Strupp, B. J., \& Levitsky, D. A. (1984). Social transmission of food preferences in adult hooded rats (Rattus norvegicus). Journal of Comparative Psychology, 98, 257-266.

(Manuscript received May 10, 1999,

revision accepted for publication October 19, 1999.) 